\title{
Wogonin a Promising Component of Scutellaria baicalensis: A Review on its Chemistry, Pharmacokinetics, and Biological Activities
}

\author{
Maha M. Hassanin ${ }^{\mathrm{a}}$, Mai F. Tolba ${ }^{\mathrm{a}, \mathrm{b}}$, Marianne G. Tadros ${ }^{\mathrm{a}}$, Mohamed M. Elmazar ${ }^{\mathrm{c}}$, Abdel-Nasser Singab ${ }^{\mathrm{b}, \mathrm{d}^{*}}$ \\ ${ }^{a}$ Department of Pharmacology and Toxicology, Faculty of Pharmacy, Ain Shams University, Cairo 11566, Egypt \\ ${ }^{b}$ Center of Drug Discovery Research and Development, Faculty of Pharmacy, Ain Shams University, Cairo 11566, \\ Egypt \\ ${ }^{c}$ Department of Pharmacology and Toxicology, Faculty of Pharmacy, The British University in Egypt, Egypt \\ ${ }^{d}$ Department of Pharmacognosy, Faculty of Pharmacy, Ain Shams University, Cairo 11566, Egypt
}

\begin{abstract}
Scutellaria baicalensis Georgi (Huang-Qin or Chinese skullcap) is a native medicinal plant in China that is commonly used for the treatment of seizures, viral infections, and cancer. The numerous pharmacodynamics of this plant is referred to as its rich content of flavones (baicalin and wogonoside) and their corresponding aglycones (baicalein and wogonin). Wogonin is one of the most extensively investigated active components of Scutellaria baicalensis. A multitude of preclinical studies indicated that wogonin possesses many pharmacological activities including anti-inflammatory, antioxidant, cytotoxic, neuroprotective, antidiabetic and antiviral effects. However, studies regarding the toxicity profile of wogonin are lacking. This review focuses on the recently published data regarding the chemistry and the pharmacokinetic profile of wogonin. Moreover, it highlights some of wogonin's well documented biological activities such as cytotoxic, neuroprotective, antidiabetic and antiviral activities. The information in this review encourages further investigations to elucidate the wogonin's full toxicological profile for verification of the safety of wogonin and the determination of the maximal tolerable dose (MTD) to be able to extrapolate wogonin's benefits to the clinical setting.
\end{abstract}

Keywords: wogonin; neuroprotective; antidiabetic; anti-inflammatory; antioxidant; pharmacokinetics

*Correspondence | Abdel-Nasser Singab; Department of Pharmacognosy and Phytochemistry; Faculty of Pharmacy, Ain Shams University, Cairo, Egypt. Email: nasersingab@hotmail.com

Citation | Hassanin MM, Tolba MF, Tadros MG, Elmazar MM, Singab AB, 2019. Wogonin a Promising Component of Scutellaria baicalensis:

A Review on its Chemistry, Pharmacokinetics and Biological Activities. Arch Pharm Sci ASU 3(2): 170-179

DOI: $10.21608 /$ aps.2019.18854.1016

Print ISSN: 2356-8380. Online ISSN: 2356-8399.

Received 03 November 2019. Accepted 14 November 2019.

Copyright: ${ }^{\circledR} 2019$ Hassanin et al. This is an open-access article licensed under a Creative Commons Attribution 4.0 International License (CC BY 4.0), which permits unrestricted use, distribution, and reproduction in any medium, provided the original author(s) and source are credited. Published by: Ain Shams University, Faculty of Pharmacy

\section{INTRODUCTION}

Natural products have long been an important player in the process of drug discovery. Flavonoids comprise an important category of bioactive compounds of natural origin. Scutellaria baicalensis Georgi is a native Chinese medicinal plant. Its significant medicinal value increases progressively and over 5000 tons have been required in the traditional medicine market [1]. Wogonin is a promising component of Scutellaria baicalensis. Several studies elucidated that wogonin has a multitude of beneficial biological properties. It has antiinflammatory, antitumor, neuroprotective, anxiolytic and antiviral [2-4]. Numerous experiments conducted in vitro and in vivo have 
demonstrated wogonin's excellent anti-cancer properties [5]. This promising compound has a well-documented antioxidant and antiinflammatory properties, which are probably the major underlying mechanisms responsible for most of its biological activities. The present review discusses wogonin chemistry, pharmacokinetics, and some of its well documented biological activities through summarizing studies published within the time range 2010-2019. Numerous preclinical studies support the beneficial biological activity of wogonin. However, there is a paucity of studies regarding wogonin toxicity profile and safety data. The information covered in this review encourages further investigations of wogonin to assess the maximal tolerable dose (MTD) of wogonin to be able to extrapolate its benefits to the clinical setting after the verification of its safety.

\subsection{Wogonin Chemistry}

Wogonin was first isolated from the Chinese flowering plant Scutellaria baicalensis that belongs to the Lamiaceae family [6]. Wogonin can be prepared either by extraction or by chemical synthesis, either by cyclization of 1,3diaryl-diketone or by Wessely-Moser rearrangement [7]. Wogonin's chemical name is 5,7-dihydroxy-8-methoxy flavone. Its molecular weight is $284.267 \mathrm{~g} / \mathrm{mol}$ [8]. The chemical structure of wogonin is depicted in Fig. 1.

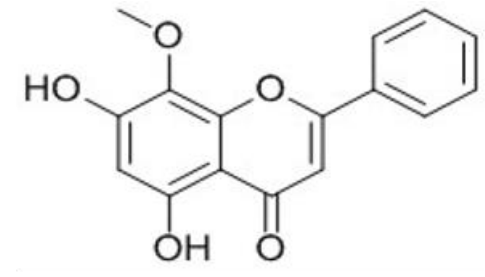

Fig.1. The chemical structure of wogonin

Wogonin is a crystalline solid soluble in organic solvents including ethanol, dimethyl sulfoxide (DMSO), and dimethylformamide (DMF) and has limited solubility in aqueous buffers [6].

\subsection{Pharmacokinetics}

The pharmacokinetic studies of wogonin are important to help the investigation of its pharmacological activities in vivo. The $\mathrm{LD}_{50}$ of wogonin administered to rats by the intravenous route was $286.15 \mathrm{mg} / \mathrm{kg}$. The elimination halflife of wogonin $(40 \mathrm{mg} / \mathrm{kg})$ after intravenous administration was $14 \mathrm{~min} . \mathrm{C}_{\max }$ value of wogonin $(100 \mathrm{mg} / \mathrm{kg})$ was $300 \mathrm{ng} / \mathrm{mL}$ after 28 min. of intragastric infusion [9]. Wogonin was rapidly distributed to all rat tissues with markedly higher distribution to liver and kidney tissues [9].

Only $21 \%$ of wogonin was excreted unchanged in rat feces, urine, and bile [10] Wogonin exhibits a high plasma protein binding (>90\%) according to studies in rat plasma [10] At high doses of wogonin, nonlinear pharmacokinetic behavior was observed with a disproportionate increase in plasma levels [11] This behavior was due to partial saturation of clearance pathways in addition to other enzymes responsible for wogonin metabolism [12]. The oral bioavailability of wogonin is low $(1.10 \%)$ [9] which could be attributed to its low solubility and the extensive exposure to gastrointestinal first-pass effect [13]. Wogonin can cross the Blood-Testis Barrier (BTB) effectively [14]. Based on the pharmacokinetic data discussed above, wogonin cannot be administered orally due to its low bioavailability. This fact encourages the development of wogonin nanoformulations to improve its oral bioavailability.

\subsection{Cytotoxic Activity}

A multitude of studies reported a broadspectrum anticancer activity for wogonin through a diversity of mechanisms as summarized in Fig. 2. Wogonin enhanced TNF-related apoptosisinducing ligand (TRAIL) induced apoptosis in 
malignant cells in vitro through antiapoptotic proteins downregulation. These proteins include the long form of cellular FLICE-like inhibitory protein (cFLIP L), X-linked inhibitor of apoptosis protein (XIAP) and cellular inhibitor of apoptosis protein 1 and 2 (cIAP-1 and cIAP-2) [15]. Wogonin robustly induced intracellular reactive oxygen species (ROS) accumulation in cancer cells [16]. Wogonin was reported to be a promising agent in the treatment of human colorectal cancer [17]. Wogonin interfered with the transcriptional activity of the T-cell factor/lymphoid enhancer-binding factor (TCF/LeF) through inhibition of $\beta$-catenin mediated transcription and suppressed the kinase activity of Cyclin-Dependent Kinase 8 (CDK8) [17]. Treatment with wogonin also suppressed cell proliferation and induced G0/G1 cell cycle arrest [18] and inhibited cancer cell invasion [19]. Wogonin treatment significantly induced mitochondrial damage and apoptosis via the modulation of B-cell lymphoma 2 (Bcl-2) and Bcl-2 Associated X (Bax) protein expression. It was reported to decrease $\mathrm{Bcl}-2$ expression and increase Bax protein, leading to mitochondrial dysfunction, caspase activation and PARP cleavage in HT29 cells [20]. Previous in vitro studies showed that wogonin inhibited tumor angiogenesis by downregulating the expression of the hypoxia-inducible factor- $1 \alpha$ protein (HIF$1 \alpha)$ and monocarboxylate transporter-4 (MCT-4) [21, 22]. Moreover, wogonin increased the sensitivity of ovarian cancer cells through modulating PI3K/AKT signaling pathway [23].

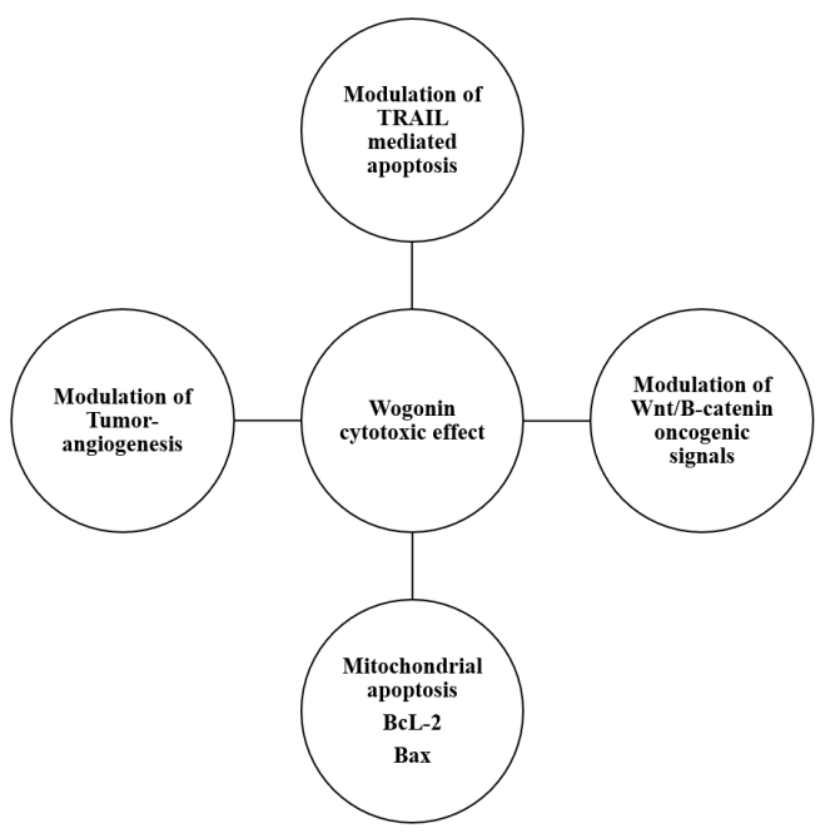

Fig. 2. A diagram summarizing the chief aspects of wogonin's cytotoxic effects

\subsection{Neuroprotective Activity}

Flavonoids can modulate the neuronal functions and protect against age-related neurodegeneration [24]. Neuroprotection against cerebral ischemia is thought to be mainly via glutamate receptor modulation and suppression of both inflammatory reactions and oxidative stress [25]. Anti-inflammatory and antioxidant activities of wogonin are responsible for its neuroprotective activity [26]. 
The neuroprotective effect of wogonin was tested in two brain injury models; transient global ischemia by four-vessel occlusion and systemic injections of kainite to elicit excitotoxic injury. Wogonin inhibited the inflammatory activation of microglia leading to the reduction of hippocampal neurons death [27]. Wogonin inhibited inflammatory activation of cultured brain microglia and suppressed lipopolysaccharide (LPS) -induced tumor necrosis factor (TNF)- $\alpha$, interleukin (IL)- $1 \beta$ and nitric oxide (NO) production [27]. It was reported that wogonin exhibited significant inhibition of Nicotinamide adenine dinucleotide phosphate (NADPH)-induced lipid peroxidation in rat brain cortex mitochondria [28]. Wogonin exhibited marked inhibition of lipid peroxidation in rat brain tissues [29]. In vitro study reported that wogonin downregulated the genetic expression of Notch-1 indicating that wogonin has a promising therapeutic effect for the treatment of retinal degenerative diseases [30].

It is noteworthy that flavonoids can also act as modulators for the $\gamma$-aminobutyric acid (GABAA) receptor [31]. Wogonin maximally upregulated the expressions of the presynaptic protein, synapsin I and postsynaptic protein PSD95 and promoted the differentiation of Neural Progenitor Cells (NPCs) into mature neurons in vivo [32]. Furthermore, wogonin enhanced the differentiation rate of hippocampal precursor cells induced by platelet-derived growth factor (PDGF) [32]. In global ischemia models, wogonin decreased the inflammatory mediators; inducible nitric oxide synthase (iNOS) and $\mathrm{TNF}_{\alpha}$, in the hippocampus tissues [33]. Additionally, wogonin elicited vasodilatory effects via the interference with extracellular $\mathrm{Ca}^{2+}$ influx and $\mathrm{Ca}^{2+}$ release from the endoplasmic reticulum [34]. Wogonin counteracted fluid precision injury in vivo [2] and showed a neuroprotective effect against Alzheimer's disease by downregulating the amyloidogenic pathway via decreasing Bax expression [35]. In a focal ischemia model, wogonin repressed cerebral ischemic injury and the infarct volume through activated microglial cells inhibition [36, 37]. Neuronal cell damage induced by deprivation of oxygen and glucose in rat hippocampal culture was counteracted by wogonin [25]. The cell viability of rat dorsal root ganglion (DRG) neurons was significantly enhanced by wogonin. On the other hand, the number of apoptotic propidium iodide positive DRG neurons was decreased [21]. Furthermore, wogonin decreased the activation glucoseregulated protein 78 (GRP78), GRP94, C/EBPhomologous protein, active caspase 12 and 3, phosphorylation of pancreatic ER stress kinase, and eukaryotic initiation factor 2 alpha (eIF2a) [38].

Wogonin pretreatment was reported to the downregulated expression of the CHOP protein level in tunicamycin-induced DRG neurons [38]. Wogonin also counteracted tunicamycin-induced depletion of glutathione (GSH) with subsequent reduction in lactate dehydrogenase (LDH) leakage [38]. The mechanisms of wogonin's neuroprotective effects are summarized in Fig. 3.

\subsection{Antidiabetic Activity}

Diabetes pathogenesis is strongly correlated with inflammation and increased oxidative stress [39-41]. As discussed above, wogonin possesses both antioxidant and anti-inflammatory properties [42]. In vivo study was conducted in mice followed by in vitro mechanistic investigations using 3T3-L1 cells [43]. Wogonin treated group showed decreased weight gain and improved glucose tolerance. The levels of cholesterol and insulin were significantly decreased. Wogonin enhanced the expression of Peroxisome proliferator-activated receptors $\alpha$ (PPAR $\alpha$ ) and PPAR $\gamma$ in white adipose tissue which in turn mediated several genes involved in 
glucose and lipid metabolism and adiponectin expression level in white adipose tissue [43]. Wogonin ameliorated insulin sensitivity by downregulating insulin levels and decreasing blood glucose [38]. Wogonin improved dyslipidemia by lowering cholesterol levels in macrophages and apolipoprotein E [44]. The aforementioned activities of wogonin were via $5^{\prime}$ adenosine monophosphate-activated protein kinase (AMPK) activation [45].

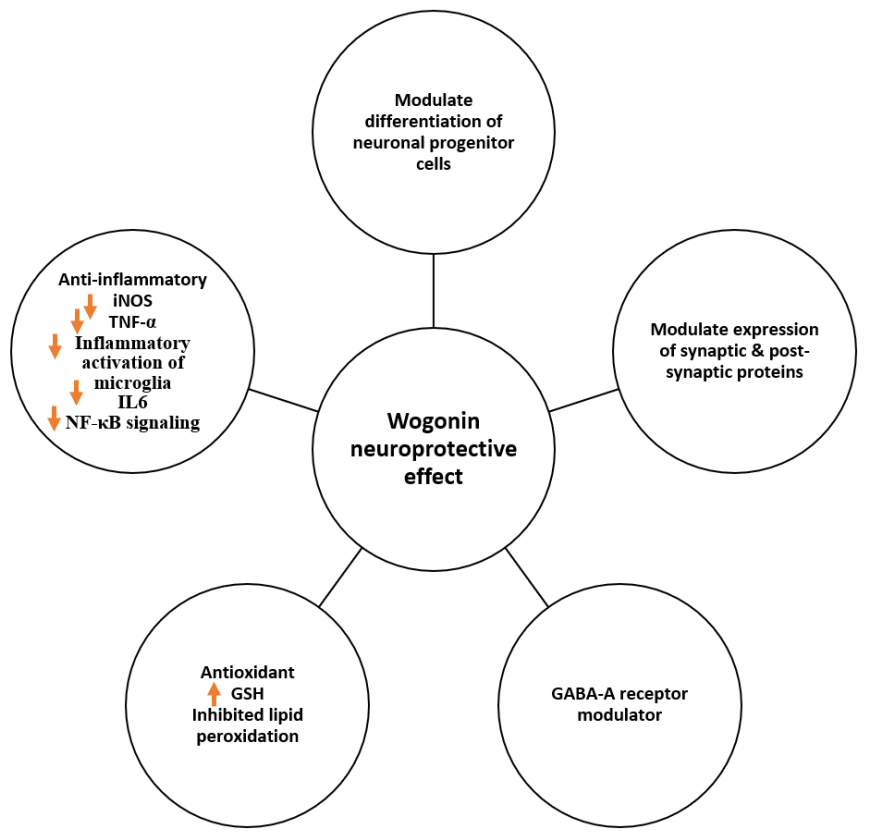

Fig. 3. The schematic diagram for the mechanisms of wogonin's neuroprotective effects

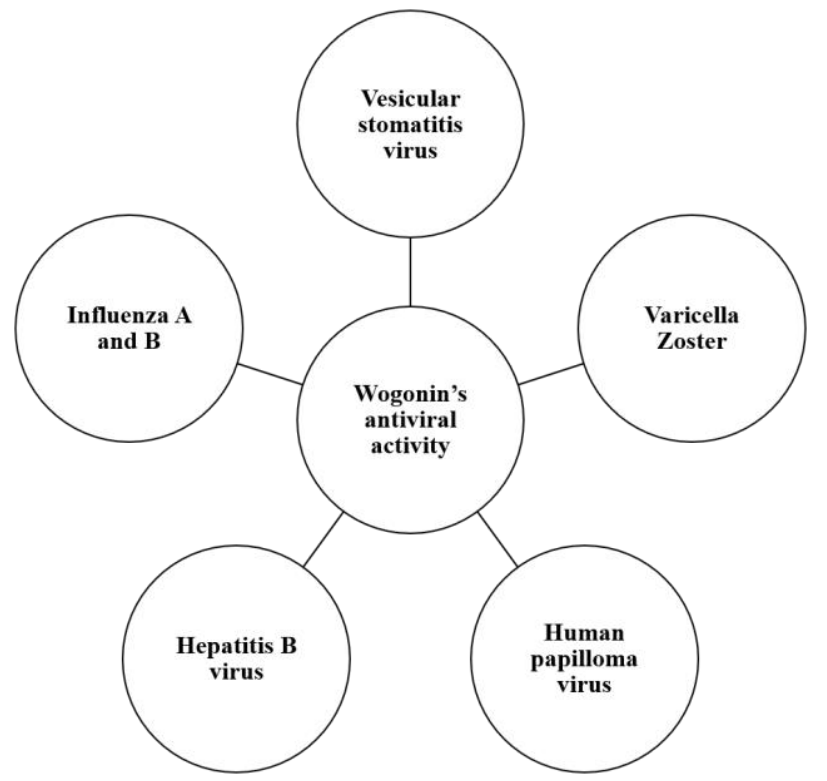

Fig. 4. Wogonin exhibits a broad-spectrum antiviral activity 
Wogonin counteracted the increase in serum osteopontin levels and downregulated osteopontin expression in adipose tissue from type 1 diabetic mice induced by streptozotocin [46]. Moreover, wogonin upregulated PPAR $\alpha$ expression [46]. Furthermore, the levels of both c-Fos and phosphorylated c-Jun levels were reduced by wogonin treatment in adipose tissue and in vitro in 3T3-L1 adipocytes [47]. Molecular docking study showed that wogonin had a promising antidiabetic activity via Glucose transporter type 4 (GLUT4) [48] as wogonin increased its signaling thus modulating the AKT/GLUT4 pathway [49]. Besides, wogonin significantly suppressed p38 MAPK phosphorylation [46]. PPAR $\alpha$ has been reported to negatively regulate osteopontin expression by negative intervention with c-Fos/c-Jun [50]. Based on the aforementioned studies we can conclude that wogonin has valuable actions on blood glucose level, insulin sensitivity, and lipid metabolism. Wogonin is a beneficial treatment for the management of several metabolic disorders including diabetes.

\subsection{Antiviral Activity}

Studies have shown that wogonin suppresses the replication of multiple viruses, such as vesicular stomatitis virus [51] and varicellazoster virus [52] and human papillomavirus [53]. Wogonin had potent suppressive activity against HBV antigens secretion. Also, it proportionally downregulated the expression of HBV DNA. In vivo and in vitro studies showed that wogonin had a powerful anti-HBV activity [54]. The wogonin treatment effectively suppressed both influenza A and B virus replication in MadinDarby Canine Kidney cells and human lung epithelial cells [3]. The potent anti-influenza activity of wogonin was mediated by the regulation of AMPK activation $[3,52]$. The spectrum of wogonin's antiviral activities is summarized in Fig. 4.

\section{Conclusion}

Wogonin is a promising flavonoid derived from Scutellaria baicalensis. This review addresses the up-to-date studies about wogonin chemistry, pharmacokinetics, biological activities. As discussed above wogonin's antiinflammatory and antioxidant activities are the main underlying mechanisms for its biological activities. However, until now there is a paucity of information regarding wogonin's genotoxic potential and safety profile on both the short term and the long term. Considering the translational potential of wogonin in fostering effective alternative therapeutic strategies, the elucidation of its safety profile warrants further investigations.

\section{Declarations}

The authors have no relevant affiliations or financial involvement with any organization or entity with a financial interest in or financial conflict with the subject matter or materials discussed in the manuscript. This includes employment, consultancies, honoraria, stock ownership or options, expert testimony, grants or patents received or pending, or royalties. No writing assistance was utilized in the production of this manuscript.

\section{Ethics Approval and Consent to Participate:}

Not applicable.

\section{Consent to Publish:}

All the authors approved the final manuscript and agreed on the publishing of the submitted work in the APS journal.

\section{Availability of Data and Materials:}

All data generated or analyzed during this study are included in this published article in the main manuscript. 


\section{Competing Interests:}

The authors declare that there is no conflict of interest.

\section{Funding Statement:}

No funding was received.

\section{Authors' Contributions:}

The review idea was by M.F.T; the manuscript was drafted by M.H; All authors reviewed and approved the final manuscript.

\section{Acknowledgement:}

The authors would like to acknowledge all colleagues in the Department of Pharmacology and Toxicology, Faculty of Pharmacy, Ain Shams University for their support.

\section{REFERENCES}

1. Yan B, Xu W, Su S, Zhu S, Zhu Z, Zeng H, et al. Comparative analysis of 15 chemical constituents in Scutellaria baicalensis stem-leaf from different regions in China by ultra-high performance liquid chromatography with triple quadrupole tandem mass spectrometry. J Sep Sci, 2017. 40(18): p. 3570-3581 DOI: $10.1002 /$ jssc. 201700473.

2. Umemoto $\mathrm{Y}$, Patel $\mathrm{A}$, Huynh $\mathrm{T}$, and Chitravanshi VCJEjop. Wogonin attenuates the deleterious effects of traumatic brain injury in anesthetized Wistar rats. 2019. 848: p. 121-130 DOI: 10.1016/j.ejphar.2019.01.035.

3. Seong R, Kim J, and Shin OJAv. Wogonin, a flavonoid isolated from Scutellaria baicalensis, has anti-viral activities against influenza infection via modulation of AMPK pathways. 2018. 62(1): p. $78-85$ DOI: 10.4149/av_2018_109.

4. Kim KA, Jung JH, Choi YS, Kang G and Kim STJA. Anti-inflammatory effect of wogonin on allergic responses in ovalbumin-induced allergic rhinitis in the mouse. 2018. 9: p. 2152656718764145

DOI:

\section{$10.1177 / 2152656718764145$.}

5. Huynh DL, Sharma N, Kumar Singh A, Singh Sodhi S, Zhang JJ, Mongre RK, et al. Antitumor activity of wogonin, an extract from Scutellaria baicalensis, through regulating different signaling pathways. Chin J Nat Med, 2017. 15(1): p. 15-40 DOI: $10.1016 / \mathrm{s} 1875-$ 5364(17)30005-5.

6. Tai MC, Tsang SY, Chang LY, and Xue H. Therapeutic potential of wogonin: a naturally occurring flavonoid. CNS Drug Rev, 2005. 11(2): p. $141-50$ DOI: 10.1111/j.15273458.2005.tb00266.x.

7. Wessely F and Moser GHJMfCCM. Synthese und Konstitution des Skutellareins. 1930. 56(1): p. 97-105.

8. Zhao L, Chen Z, Zhao Q, Wang D, Hu R, You $\mathrm{Q}$, et al. Developmental toxicity and genotoxicity studies of wogonin. 2011. 60(2): p. 212-217 DOI: 10.1016/j.yrtph.2011.03.008.

9. Qi Q, Peng J, Liu W, You Q, Yang Y, Lu N, et al. Toxicological studies of wogonin in experimental animals. Phytother Res, 2009. 23(3): p. 417-22 DOI: 10.1002/ptr.2645.

10. Talbi A, Zhao D, Liu Q, Li J, Fan A, Yang W, et al. Pharmacokinetics, tissue distribution, excretion and plasma protein binding studies of wogonin in rats. Molecules, 2014. 19(5): p. 5538-49 DOI: 10.3390/molecules19055538.

11. Zhang L, Lin G, and Zuo Z. Involvement of UDP-glucuronosyltransferases in the extensive liver and intestinal first-pass metabolism of flavonoid baicalein. Pharm Res, 2007. 24(1): p. 81-9 DOI: 10.1007/s11095-0069126-y.

12. Chen YC, Shen SC, Lee WR, Lin HY, Ko CH, Shih CM, et al. Wogonin and fisetin induction of apoptosis through activation of caspase 3 cascade and alternative expression of p21 protein in hepatocellular carcinoma cells SKHEP-1. Arch Toxicol, 2002. 76(5-6): p. 351-9 DOI: $10.1007 / \mathrm{s} 00204-002-0346-6$. 
13. Li C, Zhang L, Zhou L, Wo SK, Lin G, and Zuo Z. Comparison of intestinal absorption and disposition of structurally similar bioactive flavones in Radix Scutellariae. Aaps j, 2012. 14(1): p. 23-34 DOI: 10.1208/s12248-011-93109.

14. Sterbis JR, Rice KR, Javitt MC, Schenkman NS, and Brassell SA. Fusion imaging: a novel staging modality in testis cancer. J Cancer, 2010. 1: p. 223-9 DOI: $\underline{10.7150 / \text { jca. } 1.223}$.

15. Yang L, Wang Q, Li D, Zhou Y, Zheng X, Sun $\mathrm{H}$, et al. Wogonin enhances antitumor activity of tumor necrosis factor-related apoptosis-inducing ligand in vivo through ROS-mediated downregulation of cFLIP L and IAP proteins. 2013. 18(5): p. 618-626 DOI: $10.1007 / \mathrm{s} 10495-$ 013-0808-8.

16. Lin C-C, Lin J-J, Wu P-P, Lu C-C, Chiang J-H, Kuo C-L, et al. Wogonin, a natural and biologically-active flavonoid, influences a murine WEHI-3 leukemia model in vivo through enhancing populations of T-and B-cells. 2013. 27(6): p. 733-738.

17. He L, Lu N, Dai Q, Zhao Y, Zhao L, Wang H, et al. Wogonin induced G1 cell cycle arrest by regulating $\mathrm{Wnt} / \beta$-catenin signaling pathway and inactivating CDK8 in human colorectal cancer carcinoma cells. 2013. 312: p. 36-47 DOI: 10.1016/j.tox.2013.07.013.

18. Wang Y, Zhang Y, Qian C, Cai M, Li Y, Li Z, et al. GSK3 $\beta / \beta$-catenin signaling is correlated with the differentiation of glioma cells induced by wogonin. 2013. 222(2): p. 212-223 DOI: 10.1016/j.toxlet.2013.07.013.

19. Chen P, Lu N, Ling Y, Chen Y, Hui H, Lu Z, et al. Inhibitory effects of wogonin on the invasion of human breast carcinoma cells by downregulating the expression and activity of matrix metalloproteinase-9. 2011. 282(3): p. 122-128 DOI: 10.1016/j.tox.2011.01.018.

20. Rong LW, Wang RX, Zheng XL, Feng XQ,
Zhang L, Zhang L, et al. Combination of wogonin and sorafenib effectively kills human hepatocellular carcinoma cells through apoptosis potentiation and autophagy inhibition. 2017. 13(6): p. $5028-5034$ DOI: 10.3892/ol.2017.6059.

21. Song X, Yao J, Wang F, Zhou M, Zhou Y, Wang $\mathrm{H}$, et al. Wogonin inhibits tumor angiogenesis via degradation of HIF-1 $\alpha$ protein. 2013. 271(2): p. 144-155 DOI: 10.1016/j.taap.2013.04.031.

22. Wang SJ, Zhao JK, Ren S, Sun WW, Zhang WJ, Zhang JNJE, et al. Wogonin affects proliferation and the energy metabolism of SGC-7901 and A549 cells. 2019. 17(1): p. 911918 DOI: 10.3892/etm.2018.7023.

23. Xing F, Sun C, Luo N, He Y, Chen M, Ding S, et al. Wogonin Increases Cisplatin Sensitivity in Ovarian Cancer Cells Through Inhibition of the Phosphatidylinositol 3-Kinase (PI3K)/Akt Pathway. 2019. 25: p. 6007 DOI: $10.12659 / M S M .913829$

24. Kumar GP and Khanum F. Neuroprotective potential of phytochemicals. Pharmacogn Rev, 2012. 6(12): p. 81-90 DOI: 10.4103/09737847.99898 .

25. Son D, Lee P, Lee J, Kim H, and Kim SY. Neuroprotective effect of wogonin in hippocampal slice culture exposed to oxygen and glucose deprivation. Eur J Pharmacol, 2004. 493(1-3): $\quad$ p. $\quad 99-102$ DOI: 10.1016/j.ejphar.2004.04.017.

26. Fang W, Zhou X, Wang J, Xu L, Zhou L, $\mathrm{Yu} \mathrm{W}$, et al. Wogonin mitigates intervertebral disc degeneration through the Nrf2/ARE and MAPK signaling pathways. 2018. 65: p. 539549 DOI: 10.1016/j.intimp.2018.10.024.

27. Lee H, Kim YO, Kim H, Kim SY, Noh HS, Kang SS, et al. Flavonoid wogonin from medicinal herb is neuroprotective by inhibiting inflammatory activation of microglia. Faseb j, 2003. 17(13): p. 1943-4 DOI: 10.1096/fj.03- 
0057fje.

28. Gao Z, Huang K, Yang X, and Xu H. Free radical scavenging and antioxidant activities of flavonoids extracted from the radix of Scutellaria baicalensis Georgi. Biochim Biophys Acta, 1999. 1472(3): p. 643-50 DOI: 10.1016/s0304-4165(99)00152-x.

29. Cho J and Lee HK. Wogonin inhibits excitotoxic and oxidative neuronal damage in primary cultured rat cortical cells. Eur J Pharmacol, 2004. 485(1-3): p. 105-10 DOI: 10.1016/j.ejphar.2003.11.064.

30. Shu Q, Zhuang H, Fan J, Wang X, and Xu GJO. Wogonin induces retinal neuron-like differentiation of bone marrow stem cells by inhibiting Notch-1 signaling. 2017. 8(17): p. 28431.

31. Hanrahan JR, Chebib M, and Johnston GA. Flavonoid modulation of GABA(A) receptors. Br J Pharmacol, 2011. 163(2): p. 234-45 DOI: 10.1111/j.1476-5381.2011.01228.x.

32. Lim JS, Yoo M, Kwon HJ, Kim H, and Kwon YK. Wogonin induces differentiation and neurite outgrowth of neural precursor cells. Biochem Biophys Res Commun, 2010. 402(1): p. 42-7 DOI: 10.1016/j.bbrc.2010.09.098.

33. Chen CC, Hung TH, Wang YH, Lin CW, Wang PY, Lee CY, et al. Wogonin improves histological and functional outcomes, and reduces activation of TLR4/NF-kappaB signaling after experimental traumatic brain injury. PLoS One, 2012. 7(1): p. e30294 DOI: 10.1371/journal.pone.0030294.

34. Qu JT, Zhang DX, Liu F, Mao HP, Ma YK, Yang Y, et al. Vasodilatory Effect of Wogonin on the Rat Aorta and Its Mechanism Study. Biol Pharm Bull, 2015. 38(12): p. 1873-8 DOI: 10.1248/bpb.b15-00444.

35. Huang D-S, Yu Y-C, Wu C-H and Lin J-YJEBC. Protective Effects of Wogonin against Alzheimer's Disease by Inhibition of Amyloidogenic Pathway, Medicine, 2017. DOI:
$10.1155 / 2017 / 3545169$.

36. Piao HZ, Jin SA, Chun HS, Lee JC, and Kim WK. Neuroprotective effect of wogonin: potential roles of inflammatory cytokines. Arch Pharm Res, 2004. 27(9): p. 930-6 DOI:10.1007/bf02975846.

37. Kim WK and Ko KH. Potentiation of Nmethyl-D-aspartate-mediated neurotoxicity by immunostimulated murine microglia. J Neurosci Res, 1998. 54(1): p. 17-26 DOI: 10.1002/(sici)10974547(19981001)54:1<17::aid-jnr3>3.0.co;2-k.

38. Xu S, Zhao X, Zhao Q, Zheng Q, Fang Z, Yang $\mathrm{X}$, et al. Wogonin prevents rat dorsal root ganglion neurons death via inhibiting tunicamycin-induced ER stress in vitro. Cell Mol Neurobiol, 2015. 35(3): p. 389-398 DOI: 10.1007/s 10571-014-0134-x.

39. Rochette L, Zeller M, Cottin Y, and Vergely C . Diabetes, oxidative stress and therapeutic strategies. Biochim Biophys Acta, 2014. 1840 (9): $\quad$ p. $\quad 2709-29$ DOI: 10.1016/j.bbagen.2014.05.017.

40. Fernandez-Garcia JC, Cardona F, and Tinahones FJ. Tinahones, Inflammation, oxidative stress and metabolic syndrome: dietary modulation. Curr Vasc Pharmacol, 2013. 11(6): p. $\quad 906-19$ DOI: $\underline{10.2174 / 15701611113116660175 .}$.

41. Sifuentes-Franco S, Padilla-Tejeda DE, Carrillo-Ibarra S, and Miranda-Díaz AGJijoe. Oxidative stress, apoptosis, and mitochondrial function in diabetic nephropathy, 2018. DOI:10.1155/2018/1875870.

42. Lee YM, Cheng PY, Chen SY, Chung MT, and Sheu JR. Wogonin suppresses arrhythmias, inflammatory responses, and apoptosis induced by myocardial ischemia/reperfusion in rats. $\mathrm{J}$ Cardiovasc Pharmacol, 2011. 58(2): p. 133-42 DOI: 10.1097/FJC.0b013e31821a5078.

43. Yang T, Liu H, Zhao B, Xia Z, Zhang Y, Zhang $\mathrm{D}$, et al. Wogonin enhances intracellular 
adiponectin levels and suppresses adiponectin secretion in 3T3-L1 adipocytes. 2016: p. EJ160158 DOI:10.1507/endocrj.EJ16-0158.

44. Chen CY, Shyue SK, Ching LC, Su KH, $\mathrm{Wu}$ YL, Kou YR, et al. Wogonin promotes cholesterol efflux by increasing protein phosphatase 2B-dependent dephosphorylation at ATP-binding cassette transporter-A1 in macrophages. J Nutr Biochem, 2011. 22(11): p. 1015-21 DOI: 10.1016/j.jnutbio.2010.08.014.

45. Coughlan KA, Valentine RJ, Ruderman NB, and Saha AK. AMPK activation: a therapeutic target for type 2 diabetes? Diabetes Metab Syndr Obes, 2014. 7: p. 241-53 DOI: 10.2147/dmso.S43731.

46. Zhang YM, Li MX, Tang Z, and Wang CH. Wogonin suppresses osteopontin expression in adipocytes by activating PPARalpha. Acta Pharmacol Sin, 2015. 36(8): p. 987-97 DOI: 10.1038/aps.2015.37.

47. Zhang Y-m, Li M-x, Tang Z, and Wang ChJAPS. Wogonin suppresses osteopontin expression in adipocytes by activating PPAR $\alpha$. 2015. 36(8): p. 987 DOI: 10.1038/aps.2015.37.

48. Selvaraj JJIJoGP. Identification of new antidiabetic agents targeting GLUT4 protein using in silico analysis. 2019. 12(04) DOI: 10.22377/ijgp.v12i04.2269.

49. Khan S and Kamal MAJCpd. Wogonin Alleviates Hyperglycemia Through Increased Glucose Entry into Cells Via AKT/GLUT4 Pathway. 2019. 25(23): p. 2602-2606. DOI: $10.2174 / 1381612825666190722115410$.

50. Khan S, Zhang D, Zhang Y, Li M and Wang CJM. Wogonin attenuates diabetic cardiomyopathy through its anti-inflammatory and anti-oxidative properties, endocrinology, 2016. 428: $\quad$ p. $101-108$ DOI:10.1016/j.mce.2016.03.025.

51. Błach-Olszewska Z, Jatczak B, Rak A, Lorenc M, Gulanowski B, Drobna A, et al. Production of cytokines and stimulation of resistance to viral infection in human leukocytes by Scutellaria baicalensis flavones. 2008. 28(9): p. 571-582 DOI:10.1089/jir.2008.0125.

52. Choi E-J, Lee C-H, Kim Y-C, and Shin OSJJoFF. Wogonin inhibits Varicella-Zoster (shingles) virus replication via modulation of type I interferon signaling and adenosine monophosphate-activated protein kinase activity. 2015. 17: p. 399-409 DOI: 10.1016/j.jff.2015.05.031.

53. Kim MS, Bak Y, Park YS, Lee DH, Kim $\mathrm{JH}$, Kang JW, et al. Wogonin induces apoptosis by suppressing E6 and E7 expressions and activating intrinsic signaling pathways in HPV16 cervical cancer cells. 2013. 29(4): p. 259-272 DOI:10.1007/s10565-013-9251-4

54. Guo Q, Zhao L, You Q, Yang Y, Gu H, Song $\mathrm{G}$, et al. Anti-hepatitis B virus activity of wogonin in vitro and in vivo. 2007. 74(1): p. 1624 DOI: 10.1016/j.antiviral.2007.01.002 